\title{
WHO PERPETRATES VIOLENCE ON OWN SPOUSES? EVIDENCE FROM INDIA
}

\author{
Bigi Thomas ${ }^{1 *}$, Trivedi H.P ${ }^{1}$, Rema Subhash ${ }^{1}$ and Sangita N. Pathak ${ }^{1}$ \\ ${ }^{1}$ Sardar Patel University, Gujarat, India
}

\begin{abstract}
Perpetration of violence by men on their spouses is taking place around the world while a general understanding of the underlying precipitating factors for this violence remains limited and significant knowledge about its root causes is lacking. It is very important to understand the version of spouse violence from the perpetrator's perspectives too in order to have a complete comprehension of this violence and their violent behavior. A 24 item Men's Childhood Experience of Gender Inequity Scale [MCE-GE] and an 18 item Men's Childhood Experience of Violence Scale [MCE-V] are developed as part of this study as there were no cultural context tools available to assess these variables. In order to find out whether their childhood gender inequity attitude and violence experiences bear any impact on the prevalence of spouse violence of men, a study in multiple sites representing a range of gender equality and development indices within Gujarat, India is conducted and the findings indicate that there are very strong statistically significant links between childhood violence experiences and the perpetration of violence against women in adulthood, and this cycle of violence is facilitated and fuelled by the perpetrators' childhood gender inequity experiences.
\end{abstract}

Keywords: childhood violence experiences, childhood gender inequity experiences, spouse violence, perpetration of violence

\section{Introduction}

Women around the world experience staggering levels of all types of violence by their spouses or intimate partners. This leads to complete devastation in their lives and blocks their overall development. Yet a general understanding about the underlying precipitating factors for intimate partner violence remains limited and significant knowledge about its root causes is lacking in the society even though some studies found that the factors which lead violence against women are unequal power relations, demographic diversities, gender hierarchies and power imbalance in family itself. It is only recently researchers started trying to find out the reasons behind this human rights violation inflicted upon women by their own husbands.

A 2014 study by the Washington based women's rights and anti-poverty organization the International Center for Research on Women highlighted some incredible numbers. Nearly a fourth of the male survey respondents in India reported perpetrating sexualized violence at some point, a majority of them against an intimate partner- a girl friend or a wife. At the same time between 6 and 59 percent of ever-partnered women experience sexual violence (whether by a partner or non-partner) in their lifetimes.

This study contributes significantly to the body of evidence by exploring the prevalence of spousal violence as well as its link with childhood gender inequity and violence experiences of perpetrators. In addition to that it endows with a distinctive input to existing research on intimate partner violence by developing two standardized tools to measure the child hood gender inequity and violence experiences of men in a country like India.

\section{Violence on Spouse: An overview}

Violence against women is one of the most extreme manifestations of gender power inequalities used by many men to exert control and dominance over women (ICRW, 2012). Intimate partner violence refers to any 
behavior within an intimate relationship that causes physical, psychological or sexual harm to those in that relationship. It includes acts of physical aggression, psychological abuse, forced sexual intercourse or any other controlling behavior (WHO, 2015). It may include a single act of violence, or a number of acts that form a pattern of abuse. This can have serious-and sometimes fatal-consequences for victims and for those who see or hear the violence (Department of Justice, Canada 2017).

Available literature suggests various reasons behind violence against women. While some argue that hierarchical gender relations, perpetuated through gender socialization and socio-economic inequities, are the root causes of violence against women (Heise et al. 1994), a multi-country study in Chile, India, Egypt and Philippines identified regular alcohol consumption by the husband or partner as a risk factor for any life time intimate partner violence across all four study countries (WHO 2015).

A National Seminar on violence against women sponsored by Indian Council of Social Science Research (ICSSR), MHRD, Government of India, New Delhi and Himachal Pradesh University, Shimla on 21st \& 22nd August 2013 reported that the causes and factors of violence against women include entrenched unequal power relations between men and women that foster violence and its acceptability, aggravated by cultural and social norms, economic dependency, poverty and alcohol consumption etc.

Early childhood experiences of gender inequality have been found in many studies to shape people's views and behaviors in their later life (Gil-Gonzales et al. 2008; UNICEF 2007; WHO, 2005; Heise, 1998). Intimate partner violence is a leading cause of death among adult women in the USA and is associated with maternal mortality in the UK.

Any form of violence significantly affects victim and the witness of such brutal acts. Violence in any form can erode a woman's sense of self-worth and can be incredibly harmful to her overall mental and physical wellbeing (Committee on Health Care for Underserved Women. Intimate Partner Violence, 2012). According to a study by the National Centre for Biotechnology Information, suicide attempts in India are correlated with physical and psychological intimate partner violence (Vizcarra B, 2004).

From a psychological point of view, traumatized victims of violence are emotionally worn out. They may "withdraw, turn inward, appear depressed, display difficulties with attention, school achievement, and social engagement; they may assume the role of oppositional, aggressive perpetrator" (Marans \& Cohen, 1993). Serious health problems often result from physical, emotional, and sexual forms of domestic violence.

Physical health outcomes include: injury (from lacerations to fractures and internal organs injury), unwanted Pregnancy, gynaecological problems, STDs including HIV, miscarriage, pelvic inflammatory disease, chronic pelvic pain, headaches, permanent disabilities, asthma, irritable bowel syndrome, self-injurious behaviours (smoking, unprotected sex).30 Mental health effects can include depression, fear, anxiety, low self-esteem, sexual dysfunction, eating disorders, obsessive-compulsive disorder, or post traumatic stress disorder. Fatal effects can include suicide, homicide, maternal mortality, or HIV/AIDS.

In most cases, the target of the brutal physical attack is the mother of the child. In the article Family Violence: A Review of the Literature Rudo and Powell (p.6) state that children who experience and /or witness violence in their home "become tomorrow's murderers and perpetrator of other crimes of violence".

It is known that witnessing family violence is as harmful as experiencing it directly. Often parents believe that they have shielded their children from intimate partner violence, but research indicates that children see or hear many of the incidents. Children who witness family violence suffer the same consequences as those who are directly abused. In other words, a child who witnesses intimate partner violence is experiencing a form of child abuse (Government of Canada, RCMP, 20120). 


\section{Relevance and Significance of the Study}

Although childhood trauma and violence against women are global public health issues, few population-based data from low-income and middle-income countries exist about the links between them. Even though there is evidence that the main perpetrators of intimate partner violence in almost all developing country settings are men, most of the relevant research has been mainly focused on the perspectives of women respondents (Koenig et al 2006).

A general understanding of the underlying precipitating factors for intimate partner violence in developing countries remains limited while important knowledge about its root causes is lacking. It is very important to understand the version of intimate partner violence from the perpetrator's perspectives too to have a complete comprehension of this violence and their violent behavior. To find out whether their childhood gender inequity and violence experiences bear any impact on the prevalence of IPV is essential to have relevant policy changes in the curriculum of school syllabi to inculcate a gender equity attitude among children so that to an extent they grow with a positive attitude to adolescent and adulthood stages.

To develop effective intervention programs and policies, it is vital to study the attitude and behavior of both men and women to understand this problem. Yet, most of the available studies concentrate on women's perspective of domestic violence. Studies on prevalence and patterns and the risk factors of domestic violence have viewed the male partner as perpetrators of violence, but there are few studies that reveal a male perspective on this issue. Further, research on men and violence is extremely limited in India and theory building on this issue within the Indian context has rarely been attempted. Therefore, there is an urgent need to understand the men's perspectives, along with the factors and circumstances that shape the masculinity of men in India.

While this study aims to assess men's perpetration of different types of violence against their intimate female partners in Gujarat, it seeks to assess and compare the correlations between the intimate partner violence and their early childhood gender inequity and violence experiences. The information obtained as a result of this study gives a complete picture of the reality situation of the extent of violence within the intimate relations perpetrated by men. In addition, the determinants of violence against an intimate partner also will be identified and discussed.

Moreover, the present study highlights the need to encourage and engage boys at a very early stage in gender equitable norms and practices. It also helps us to understand the importance of a gender related violence-free family environment where children should be brought up so that they develop healthy gender role concepts and practices in their entire life. This is so because childhood experiences of gender equality can make a man able to respect his spouse and can give enough space for equality in all spheres of their family lives including division of labour in domestic works. This is in fact one of the urgent needs of the day as more women are stepping out of their houses to get into the work force while many women are forced to stay back leaving their lucrative and much needed jobs, which can provide them with a feeling of identity and empowerment.

\section{Methodology}

\section{Objectives of the study}

1. To assess and compare the correlations between men's childhood gender inequity \& violence experiences and perpetration of spouse violence.

2. To guide and influence policies for active governmental intervention towards correcting gender imbalances and promoting proper gender socialization among boys and girls.

Hypotheses 
1. There exists a significant correlation between men's childhood gender inequity experiences \& and perpetration of spouse violence.

2. There exists a significant correlation between men's childhood violence experiences and perpetration of spouse violence.

\section{Research Design}

Descriptive research design is used in this study as the main purpose of this study is to describe the men's perpetration of different types of violence against their spouses and its associations with their childhood gender inequlity \& violence experiences.

\section{Universe, Sample \& Tools of Data Collection}

The sampling frame for the present study comprises of men in the age group of 18 to 50 years from Gujarat state. A multistage random sampling method is used to select the talukas, villages and households from which 1600 samples were selected. In his working paper titled "Reporting and incidence of violence against women in India, Aashish Gupta (2014) accounted that Gujarat has a comparatively higher incidence of both physical and sexual violence of women by their husbands than many other states in India.

Multiple study sites were chosen to represent a range of gender equality and development indices within Gujarat. The chosen sites include Ahmedabad with low gender equality and high development indices, Banaskantha with both low gender equality and development indices, Gandhinagar with both high gender equality and development indices and The Dangs with high gender equality and low development indices.

According to Krejcie and Morgan (1970), for the population of 10,00,000 and above required sample size is 384. Therefore, it was decided to select a total of 1600 respondents. Then for calculating number of respondents from each district keeping in mind the urban-rural ratio of the district, proportionate sampling method was used.

Detailed Interview schedule covering areas of demographical variables are used to collect the demographical variables of the respondents. Following standardized tools are used to assess their perpetration of violence on intimate partners as well as childhood violence and gender inequity experiences.

a. Intimate Partner Violence Scale: List of 18 statements are asked to the respondents which are prepared with the help of Margolin's "Domestic Conflict Scale" or "Conflict Inventory" (Margolin, G., B. Burman, R.S. John, and M. O'Brien, The Domestic Conflict Instrument, Los Angeles: University of Southern California, 1990) and Straus's "Conflict Tactics Scales" (Straus, M.A., "Measuring Intra family Conflict and Violence: The Conflict Tactics Scales," Journal of Marriage and the Family 41(1979): 75-88) to assess the level of perpetration of IPV by respondents

b. A men's Childhood experience of gender equity scale [MCE-GInE] and Men's Childhood experience of Violence scale $[\mathrm{MCE}-\mathrm{V}]$ are developed to assess respondent's violence and gender inequality experiences during childhood.

\section{Discussion}

This study was conceptualized to unearth and generate knowledge about the prevalence of violence women are subjected to by their husbands, in the study sites. Also, it aimed to discover different forms of gender inequity and violence experiences of men during their childhood. 
Links between perpetration of IPV and men's childhood violence \& gender inequity experiences were also explored. Results of the study suggest perpetration of violence on women by their spouses is prevalent in its all forms in the study sites of Gujarat even though there are clear variations in its magnitude within the sites.

\section{Childhood Violence Experiences of Men and Intimate Partner Violence}

Despite the numerous efforts taken by concerned bodies and governments, children around the world are subjected to different types of violence. Research has long confirmed the unswerving association of childhood violence experiences on adulthood behavior.

This study confirms the connections between intimate partner violence and childhood violence experiences of men as there is a statistically significant correlation between IPV and men's childhood experiences of violence at 0.00 levels. So, it is evident from this study that those men having high level of childhood violence experiences are at high risk of perpetrating different types of violence against their spouses.

Literature review supports this theory of cycle of violence as Coker and colleagues found that men were 2.5 times more likely to report exposure to IPV as adults if they had reported being physically assaulted as children. (Saenge 2000) observes from infancy to adolescence, family violence interfered with the children's growth and development.

Much research recognizes the association between having childhood violence experiences and perpetrating intimate partner violence as an adult, as it is proved to be statistically significant in each of the six surveyed countries, says an international study conducted in Chile, Croatia, India, Rwanda, Brazil and Mexico. The same study also found that adult men who are victims and witnesses of violence as children may accept violence as a conflict resolving tactic and reported that the most consistent influence on ever having perpetrated violence on spouse is having witnessed one's mother being hit by her husband or partner.

Research in family violence established evidence that abusive parents have experienced some form of abuse in their childhood. Adults who experienced and witnessed violence in their childhood had increased potential of becoming batterer themselves. A cross sectional study by Diana Gil-Gonzalez et.al (2007) suggests when an individual is being exposed to violence during their childhood it is the risk factor for spousal violence and partner violence can be a consequence of patriarchal ideology and consequence of learned violence behavior.

Research evidence showed that having experienced abuse and neglect individuals tend to engage in antisocial activities. Individual being sexually abused or assaulted as a child would further result into similar type of offending behavior and individuals having experienced of physical abuse or neglect would have higher risk factor of perpetrating violence against children and spouse.

A United Nations Multi Country Study on Men and Violence found that there is a strong relationship between men perpetrating violence against women and childhood experiences of any kind of violence. Present study strongly asserts the validity of the theory of cycle of violence as it undoubtedly proves that men's experiences of childhood trauma contribute to violence against their spouses in later life. It reinforces the already established finding of many other researches that childhood violence experiences of men are associated with their perpetration of IPV and childhood experiences control and outline men's outlooks and deeds enormously.

Correlation analysis in this study confirmed the influence of childhood violence experiences on spouse violence of men as there is significant correlation between Intimate Partner Violence and Men's Childhood Experiences of Violence i.e. $r=0.773$ is significant at 0.00 level that means higher the childhood experiences of violence amongst men, higher is the risk of perpetrating different types of violence by them on their spouses. 
By extending her support to a petition by Insia Dariwala, a filmmaker-activist-researcher said that "male child sexual abuse is an ignored reality in India", Women and Child Development Minister of India Ms. Maneka Gandhi acknowledged the gravity of this menace in India. The study by Insia Dariwala revealed a possible correlation between unresolved sexual trauma on boys and increasing violence on women and children. Boys who are sexually abused as children spend a lifetime of silence because of the stigma and shame attached to male survivors speaking out TOI (2018).

Table 1 Table showing correlations between Men's Childhood Violence Experiences and Intimate Partner Violence [MCE-V \&IPV] and Men's Childhood Gender Inequity Experiences and Intimate Partner Violence [MCE-GInE \&IPV]

\begin{tabular}{|l|l|l|l|l|}
\hline & & IPV & MCE-_GInE & MCE-_V \\
\hline \multirow{3}{*}{ IPV } & Pearson Correlation & 1 & $.981^{* *}$ & $.773^{* *}$ \\
\cline { 2 - 5 } & Sig. (2-tailed) & & .000 & .000 \\
\cline { 2 - 5 } & $\mathrm{N}$ & 1600 & 1600 & 1600 \\
\hline
\end{tabular}

\section{Men's Childhood Gender Inequity Experiences and Intimate Partner Violence}

It is an undisputed fact that what children witness or learn or experience during childhood can have an impact on their adult attitude, perception and behavior. Intimate partner violence by men are inextricably grounded and intertwined with their attitudes towards gender equality including the roles and responsibilities of males and females, mainly learned and developed from their childhood gender equality or inequality experiences. In other words, attitudes of sanctioning of men's violence on their partners are formed through the norms of gender roles they have ingrained in childhood from their own families. How a father behaves with mother, are what the son learns from his father, how his mother behaves and what all she does are what he expects from his spouse.

Unfortunately, in many societies the existing notions sanctions the dominance of males in families and their aggressiveness in intimate relations and endorses subordinate role of women in all aspects including right on her own body that men can impose their right through dominance too. [own sentences] Such beliefs have a long history in western and other cultures and have been enshrined in western legal systems (Straton, 2002) and social norms (Berkel et al., 2004) too. For example, female victims of domestic violence are judged more harshly where they are perceived to have 'provoked' aggression, for example by being verbally aggressive or in situations which might inspire their husbands' jealousy (Hillier \& Foddy, 1993; Pavlou \& Knowles, 2001).

Perpetration of violence by men on their intimate partners is taking place around the world and one of the important factors responsible for due to which women end up being victims some way or the other is the childhood gender inequity experience of perpetrators of violence. The special attention, privileges, power and care boys and men enjoy compared to girls and women in their families from childhood due to their gender, for example- served food, washed clothes, more say, more freedom etc, play a vital role in forming gender inequity attitude as well as a sense of superiority in them over women. In several cultures, parents have different socialization goals and child-rearing practices for boys and girls. For example, girls must "learn to serve others", "listen to and respect adults", and "stay at home and play". On the other hand, "naughtiness" in boys is expected and condoned.'

Table no: 1 shows strong statistically significant correlations between Intimate Partner Violence and Men's Childhood Experiences of Gender Inequity i.e. $r=0.981$ is significant at 0.000 level that means higher the childhood experiences of gender inequity, higher are the chances of men to perpetrate violence against their 
intimate partners. This finding confirmed and reiterates the connections established between intimate partner violence and men's childhood gender inequitable experiences by an IMAGES study which reported that men who had experienced or witnessed gender inequitable behavior in childhood were more likely to perpetrate IPV than those who had not.

The relationship between adherence to conservative gender norms and tolerance for violence has been documented among males in a wide variety of communities and countries, both Western and non-Western, including Arab and ultra-Orthodox Jewish communities in Israel (Haj-Yahia, 2003; and adult men and young men in Australia (De Judicibus \& McCabe, 2001).

Conversely, the more that people maintain egalitarian gender attitudes, the better are their attitudes towards violence against women. They are more likely to see violence against women as unacceptable, to define a wider variety of acts as violence or abuse, to reject victim-blaming and to support the victim, and to hold accountable the person using violence. This egalitarian attitude would get ingrained in a boy's mind only if he had the experience of his father respecting his mother with dignity and he himself was not given undue importance in own house compared to his sisters.

A review of literature describes how boys are socialized into an environment with norms about household roles and childrearing. For example, studies across the globe find that fathers tend to contribute about onethird to one-fourth of the time that mothers do in direct child care (Population Council 2001). In sum, existing literature supports the notion that boys and young men are socialized around a constellation of gender norms related to sexual and reproductive health and risk, sexuality, fatherhood, use or acceptability of violence against women, and participation in domestic chores.

The most consistent predictor of attitudes supporting the use of violence against women is attitudes towards gender roles, that is, beliefs about appropriate roles for men and women (Berkel, Vandiver, \& Bahner, 2004; Good, Heppner, Hillenbrand-Gunn, \& Wang, 1995; Simonson \& Subich, 1999). Pearson's correlation test undoubtedly indicates that those husbands having more inequitable gender experiences during childhood perpetrated more violence upon their spouses.

\section{Conclusion}

One of the important objectives of this study was to recognize those elements explain violence on spouses by husbands and whether the childhood gender inequity and violence experiences bear any impact on the prevalence of intimate partner violence. The findings demonstrate significant insights into strong links between perpetration of IPV against women in adulthood and childhood violence experiences as well as gender inequity experiences of perpetrators. In other words this study indicate that those husbands who have either experienced or witnessed violence during childhood have a higher likelihood of internalizing violence as a normal act and therefore show more propensity towards spouse violence. Similarly husbands grown up with childhood gender inequity experiences in families where rigid gender roles were strictly followed have a higher probability of developing male dominated attitude and consequently perpetrate more violence on their spouses.

It is therefore undoubtedly clear that young boys who experience violence at home, neighborhood or school tend to inflict violence on their intimate partner too. Youngsters who used to get discriminated importance due to their gender in their families also are prone to act violence on their partners. These findings strongly point towards importance of creating violence free and gender friendly family environments to our small children so that coming generations will respect their partners. Complete prevention of all types of abuses of children can, to some extent, ensure a mentally healthy generation.

At the same time eradication of age old discriminatory practices and beliefs prevailing in society in favour of boys will help them to grow up without any such self- proclaimed importance. Efforts should be taken to 
incorporate lessons of respect, equality, dignity of labour including household work from early childhood so that they can shed away the wrong beliefs they used to acquire from the society.

\section{Acknowledgements}

This article is based on a major project funded by ICSSR, New Delhi under their sponsored project scheme to us for a period of two years 2016-2018 to conduct a study titled "Intimate Partner Violence: Exploring Links with Men's Attitude towards Gender Equality and Childhood gender Inequality \& Violence experiences.”

\section{References}

Aashish, Gupta., 2014, Reporting and incidence of violence against women in India, Date of acces:24/10/2017. http://riceinstitute.org/wordpress/wp-content/uploads/downloads/2014/10/Reporting-and-incidence-of-violenceagainst-women-in-India-working-paper-final.pdf

Berkel, L., et al. 2004, Gender role attitudes, religion, and spirituality as predictors of domestic violence attitudes in white college students. Journal of College Student Development, 45(2), 119-133.

Contreras,M.,et.al., 2012,“Bridges to Adulthood: Understanding the Lifelong Influence of Men's Childhood Experiences of Violence Analyzing Data from the International Men and Gender Equality Survey. " Washington, DC: International Center for Research on women (ICRW) and Rio de Janeiro: Instituto Promundo.

Committee on Health Care for Underserved Women. Intimate Partner Violence. American College of Obstetricians and Gynecologists, Feb. 2012. https://en.wikipedia.org/wiki/Domestic_violence_in_India retrieved on $18 / 2 / 2018$

De Judicibus, M., and McCabe, M.P. (2001). Blaming the target of sexual harassment: Impact of gender role, sexist attitudes and work role, Sex Roles, 44, 401-417.

DEPARTMENT OF JUSTICE, CANADA, 2016, what is family violence? Date of access: 21/12/2016.http://www.justice.gc.ca/eng/cj-jp/fv-vf/about-apropos.html

Diana Gil, Gonzalez., et.al.2007, Childhood experiences in perpetrators as a risk factor of intimate partner violence: a systematic review, Journal of Public Health, 30(1)14-22, doi:10.1093/pubmed/fdm071 /; Advance Access Publication 6 November 2007; pg. 14 \& 21.

Ellsberg, Mary., 2008, Intimate Partner Violence and Women's Physical and Mental Health in the WHO Multicountry Study on Women's Health and Domestic Violence: An Observational Study. The Lancet 371 (2008). Date of access: 8/7/2017. https://en.wikipedia.org/wiki/Domestic_violence_in_India

Emma, Fulu., et al. 2017, Pathways between childhood trauma, intimate partner violence, and harsh parenting: findings from the UN Multi-country Study on Men and Violence in Asia and the Pacific, Date of access:18/12/2017. http://www.thelancet.com/lancetgh; Vol: May 2017; page- e512 - 522; pg: 516,517 \& 518.

Flood, Michael and Pease, Bob (2009), Factors Influencing Attitudes to Violence Against Women from. Trauma, Violence, \& Abuse, Vol 10, Issue 2, April 2009, pp 125-142, https://doi.org/10.1177/1524838009334131

García-Moreno, C. et al. 2005, WHO multi-country study on women's health and domestic violence against women: initial results on prevalence, health outcomes and women's responses, World Health Organization.

Good, G.E., et al. 1995, Sexual and psychological violence: An exploratory study of predictors in college men, Journal of Men's Studies, 4, 59-71

Greenfield, LA., et al. 1998, Analysis of data on crimes by current or former spouses, boyfriends, and girlfriends. Violence by Intimates, Washington DC: US Dept of Justice

Government of Canada, RCMP. 2012. http://www.rcmp-grc.gc.ca/cp-pc/chi-enf-abu-eng.htm retrieved on 12/3/2018.

Haj-Yahia, M.M., (2003). Beliefs about wife beating among Arab men from Israel: The influence of their patriarchal ideology. Journal of Family Violence, 18, 193-205.

Hillier, L. and Foddy, M., 1993, The role f observer attitudes in judgments of blame in cases of wife assault. Sex Roles, 29(9-10), 629-644.

ICRW,2000, Domestic violence in India, Date of acces: 23/7/2015 https://en.wikipedia.org/wiki/Domestic_violence_in_India - 8/7/15 
ICRW, 2001, Domestic Violence in India: Exploring Strategies, Promoting Dialogue, Date of access: 30/6/2017. http://www.popline.org/node/254589

Julie Pulerwitz and Gary Barker (2008); Measuring Attitudes toward Gender Norms among Young Men in Brazil, Men and Masculinities, 10(3), 322-338.

Kevin, Browne., et al. 2007, The Cycle of Violence, World Health Organization, University of Birmingham: The relationship between childhood maltreatment $\&$ the risk of later becoming a victim or perpetrator of violence

Koenig, MA., et al, 2003, Individual and community-level determinants of domestic violence in rural Bangladesh. Demography. 40:269-288

Krejcie, R.V., \& Morgan, D.W. (1970). Determining Sample Size for Research Activities. Educational and Psychological Measurement, 30, 607-610.

Lewis, G., et al. 2007, Confidential Enquiry into Maternal and Child Health. Saving Mothers' Lives: reviewing maternal deaths to make motherhood safer, 2003-2005. Seventh Report on Confidential Enquiries into Maternal Deaths in the United Kingdom. London: CEMACH

Male child sex abuse: Maneka backs petition, Times of India, Ahmedabad edition, 26 April, 2018.

Marans, S., et al.1996, Child development and adaptation to catastrophic circumstances. In Apfel, R. J. and Bennett, S. (eds.), Minefields in their hearts: The mental health of children in war and communal violence.(104 127). New Haven, CT, USA: Yale University Press, Date of access: 18/7/2015. http://www.mincava.umn.edu/documents/familyviolence/familyviolence.html.

Nanda, Priya., et al. 2012, Study on Gender, Masculinity and Son Preference in Nepal and Vietnam". New Delhi, International Center for Research on Women

Pavlou, M. and Knowles, A., 2001, Domestic violence: Attributions, recommended punishments and reporting behaviour related to provocation by the victim. Psychiatry, Psychology and Law, 8(1), 6-85.

Peter, Cronholn., et al. 2011, Intimate Partner Violence and Men's Health, Am Fam Phys, 83 (10):1165-1172

Priyali , S., 2015, “I was like his sex slave and not his wife': An Indian woman tries to criminalize marital rape, Date of access: 24/6/2017. http://www.womensmediacenter.com/women-under-siege/i-was-his-sex-slave-andnot-wife-indian-woman-criminalize-marital-rape

Rudo, Z. H., and Powell, D. S., 1996, Family violence: a review of the literature, Florida Mental Health Institute, University of South Florida.

SAENGE, A.S., 2000, Family Violence: A Review of the dysfunctional Behaviour Patterns, Date of acces: 13/7/2015. http://www.mincava.umn.edu/documents/familyviolence/familyviolence html\#rudo 1996

Simonson, K., and Subich, L.M., 1999, Rape perceptions as a function of gender-role traditionality and victimperpetrator association, Sex Roles, 40, 617-634.

Steever, EE., et al. 2001, The correlates of male adults' perceptions of their early sexual experiences. Journal of Traumatic Stress, 14(1),189-204.

Straton, J. C., 2002, Rule of thumb versus rule of law. Men and Masculinities, 5(1), 103-109.

UNESCO, 2007, Strong Foundations for Gender Equality in Early Childhood Care and Education - Advocacy Brief. Bangkok: Bangkok, page-4] http://unesdoc.unesco.org/images/0016/001611/161195eo.pdf

UNDP, 2004, Date of 24/10/2017. http://www.in.undp.org/content/dam/india/docs/human_develop_report_gujarat_2004_report.pdf retrieved on $2 / 5 / 2015$

UNICEF, 2000, Domestic Violence Against Women and Girls.

Vizcarra, B., 2004, Partner Violence as a Risk Factor for Mental Health among Women from Communities in the Philippines, Egypt, Chile, and India. National Centre for Biotechnology Information, Department of Psychology Universidad De La $\quad$ Frontera, Temuco, https://en.wikipedia.org/wiki/Domestic_violence_in_India retrieved on 18/2/2018

WHO, 2015, Intimate Partner Violence and Alcohol Fact Sheet, World Health Organisation, Date of access: 20/11/2017. http://www.who.int/violence_injury_prevention/violence/world_report/factsheets/ft_intimate.pdf on $2 / 5 / 201$ 